\title{
CREATING VALUE IN A RETAIL BUSINESS. EVIDENCE FROM THE RUSSIAN FOOD RETAIL MARKET
}

Vashakmadze Teimuraz,

Associate professor, department of business and managerial strategy, The Russian Presidential Academy of National Economy and Public Administration Executive director, RGG Capital Founder and managing director, Fin-mofel.ru

Martirosyan Emil,

Associate Professor Institute of Business Studies (IBS-Moscow) within the Russian Presidential Academy of National Economy and Public Administration; Chief Executive Officer, LLC «Rubina»

\section{Sergeeva Anastasia}

PhD student, department of general and strategic management, The Russian Presidential Academy of National Economy and Public Administration

\begin{abstract}
In the post crisis years, the Russian food retail market has skyrocketed and run ahead of the market in general. Our research reveals major value drivers and explores the value creation of companies by comparison based on $\mathrm{P} / \mathrm{B}$ ratio. The analysis of performance indicators of three biggest Russian food retailers provides evidence that $\mathrm{ROE}$ can explain the difference and positive relationship of $\mathrm{P} / \mathrm{B}$ ratio. Our findings suggest that retail companies are increasing ROE through the net profit margin improvement. In addition, we have found out that a higher Store/DC ratio has a strong correlation to ROE of a company. The key question of the paper is identifying a combination of factors that drive performance and value creation in the post-crisis period in the non-consolidated Russian food retail market. Thus, our research is aimed at providing a broader picture of factors that influence value creation in the retail market, such as cross-docking, franchising, recognition of the product matrix, management decision decentralization, focusing on core activity and commercial conditions with suppliers.
\end{abstract}

Key words: return on equity (ROE), the price-to-book ratio (P/B ratio), food retail market, net profit margin, asset turnover, gearing.

JEL: G32

\section{Introduction}

Six years have already passed since the global financial crisis of 2008. If we look at Russian food retailers, we can see that over the period from 31/12/2008 to 31/12/2013 the total market capitalization of three biggest Russian food retailers (Magnit, X5 Retail Group and Dixy) increased by 553\%, while the Russian stock index RTSI increased only by $143 \%$. In Table 1 below, we can see that companies such as Magnit and Dixy have shown a tremendous growth in the market capitalization and that X5 Retail Group has shown a little more growth than the Russian stock market.

Table 1.

Russian stock market performance vs. Russian food retailer's stock performance, 2008-2013.

\begin{tabular}{|c|c|c|c|}
\hline & 2008 & 2013 & Change in $\%$ \\
\hline RTS Index & 619,53 & 1504,08 & $+143 \%$ \\
\hline Total market capitalization of 3 Russian food retailers, in \$Bn. & 5,01 & 32,70 & $+553 \%$ \\
\hline Market capitalization of Magnit in \$Bn & 3,28 & 26,5 & $+708 \%$ \\
\hline Market capitalization of X5 Retail Group in \$Bn & 1,63 & 4,60 & $+182 \%$ \\
\hline Market capitalization of Dixy in \$Bn & 0,10 & 1,60 & $+1527 \%$ \\
\hline
\end{tabular}

An extensive amount of scientific and business literature is devoted to various aspects of value creation in different markets. In order to analyze value creation, researchers tent to use the book-to- 
market ratio (B/M) (Fama and French, 2006). Wilcox (1984) describes the interconnection between the price-to-book ratio $(\mathrm{P} / \mathrm{B})$ and return on equity ratio $(\mathrm{ROE})$. The $\mathrm{P} / \mathrm{B}-\mathrm{ROE}$ approach is one of valuation models developed from basic economic assumptions. The P/B-ROE model is an effective tool for a broad variety of uses, including the explanation of current prices and the prediction of future return differences.

Chen and Zhang (2003) predict that equity value is an increasing and convex function of profitability and earnings given book value, a linear function of book value given profitability, and a nonmonotonic and convex function of book value given earnings. The paper shows that these predicted effects are more notable for companies with greater growth opportunities.

The traditional ratio analysis utilizes the DuPont model to disaggregate the return on common equity into its return-on-assets and financial leverage components. Following this definition, the analysis can investigate the factors which influence the net profit margin on sales (the gross profit margin and operating expense control) as well as those affecting total asset turnover. According to Halsey (2001), ROE can be viewed not as the sole object of the analysis, but as an indicator reflecting underlying business dynamics. Halsey and Soybel (2001) emphasize differences in reversion rates for the components of ROE and show that most of the reversion in ROE is explained by reversion in profit margins as financial leverage and total asset turnover change slowly over time.

The process of a retailer's value creation is articulated by a retail business model. Sorescu (Sorescu et al., 2011) suggests that innovations in business models are critical for setting up a sustainable advantage in a marketplace indicated by unrelenting change, escalating customer expectations, and intense competition. The author proposes that innovations in retail business models are depicted by changes in three design components: the way in which the activities are arranged, the type of activities that are implemented, and the level of participation of the actors engaged in performing these activities. The author emphasizes the modern role of retailers as "ecosystems in which value is created and delivered to customers and, subsequently, appropriated by the retailer and its business partners". Among the factors of value appropriation, the author enumerates operational efficiency, operational effectiveness and customer lock-in, while the factors of value creation include customer efficiency, customer effectiveness and customer engagement.

Researchers explore a wide range of issues that retailers need to concentrate on in order to ensure value creation in times of severe competition. Thus, as Ganesan et al. (2009) claim, retailers need to revise their supply chain structures and strategies to adapt better to the changing environment. Effective supply chains attain an increasing importance for the financial performance of retailers. Among the factors that retailers need to consider are pricing strategies and cost controls. It is stressed by Billige (Billige, 2013) that intelligent pricing strategies would allow consumer goods companies to defend and increase profits by getting the right price for the right products for the right customers. Van Zelst (Van Zelst S. et al., 2009) highlights the importance of controlling costs claiming that in retail stores the handling of products typically forms the largest share of operational costs.

Our research is aimed at providing a broader picture by focusing on a wide selection of factors that influence value creation in the retail market, such as cross-docking, franchising, recognition of the product matrix, management decision decentralization, focusing on core activity and commercial conditions with suppliers.

\section{Research methodology}

As seen in Table 1, in 2008 Magnit and X5 Retail Group were pretty similar in size. By contrast, Dixy used to be a much smaller company. In order to analyze the value creation of companies it is important to compare the companies on a relative basis. For such a comparison, we will use the $\mathrm{P} / \mathrm{B}$ ratio. The $\mathrm{P} / \mathrm{B}$ ratio shows how many dollars investors are ready to pay for one dollar of the book value of equity, which seems to be an attractive measure of performance because it indicates the difference between the net assets (the book value of equity) of the firm and the valuation that investors assign to them.

Table 2 presents $\mathrm{P} / \mathrm{B}$ ratios by companies, from which we can see that Magnit was significantly more expensive both in 2008 and in 2013. In 2013, investors were willing to pay almost $\$ 7$ per $\$ 1$ of the book value of Magnit, while for Dixy and X5 Retail Group it was around \$1.9 per \$1 of the book value. 
P/B of Russian food retailers

\begin{tabular}{|c|c|c|}
\hline & 2008 & 2013 \\
\hline Magnit & 3,92 & 6,88 \\
\hline X5 Retail Group & 0,99 & 1,94 \\
\hline Dixy & 0,49 & 1,90 \\
\hline
\end{tabular}

In order to explore what value drivers prevailed in the Russian food retail industry in the post crisis period, the following assumptions are proposed:

Assumption 1. ROE explains the difference in $\mathrm{P} / \mathrm{B}$ ratio and its positive relationship.

Assumption 2a. Retail companies are increasing ROE through the net profit margin improvement. Assumption 2b. Retail companies are increasing ROE through the asset turnover improvement. Assumption 2c. Retail companies are increasing ROE through gearing.

Assumption 3. Each retail company has its unique approach to the management of industry relevant factors (cross-docking, franchising, regionalization of the product matrix, decentralization, focus on core activity and commercial conditions with suppliers) that affect performance and, hence, value creation.

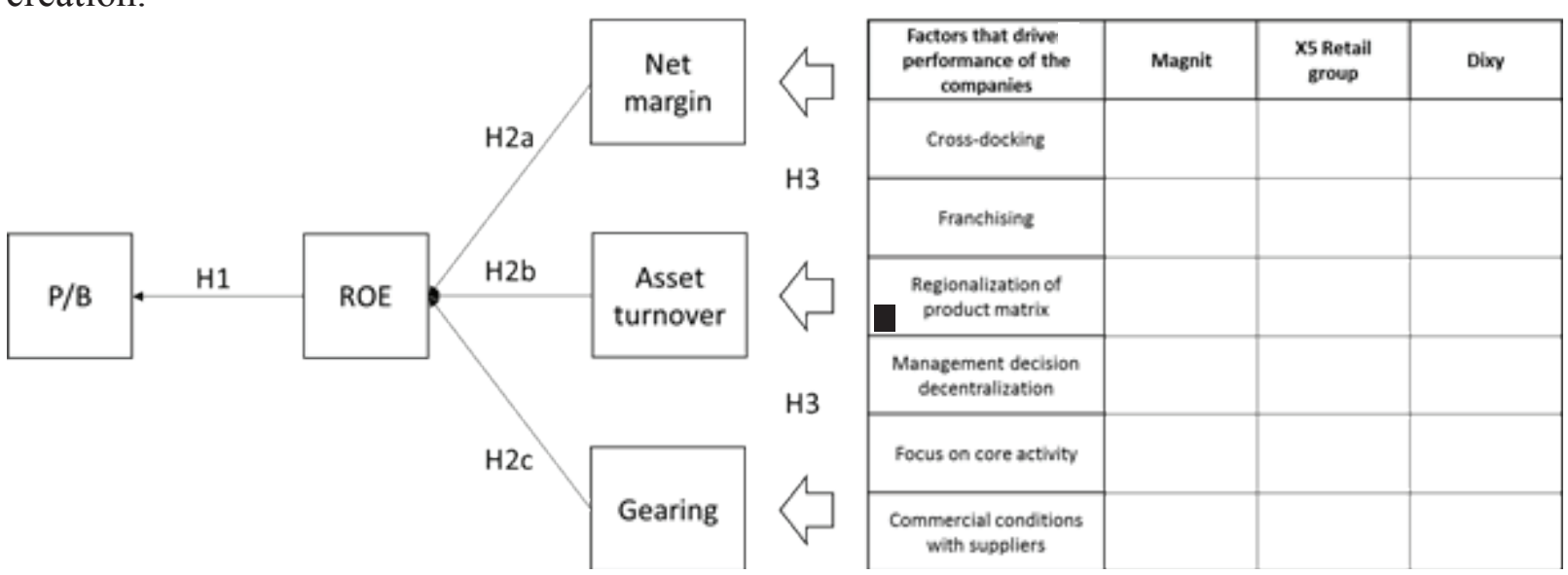

Picture 1. Factors that drive performance and value creation

Here we present the research framework that will allow us to answer the key question of the research - what a combination of factors that drive performance and value creation in the post-crisis period in the non-consolidated Russian food retail market is (Picture 1).

Picture 1. Factors that drive performance and value creation.

To test Assumption 1 we use a linear regression model:

$\frac{P}{B}=a+b^{*} R O E$

To test Assumption 2 we perform a DuPont analysis of ROE:

ROE $=\frac{\text { Net income }}{\text { Sales }} * \frac{\text { Sales }}{\text { Total assets }} * \frac{\text { Total assets }}{\text { Equity }}$,

To test Assumption 3 we carry out a benchmark analysis of each company of industry relevant factors (cross-docking, franchising, regionalization of the product matrix, decentralization, focus on core activity and commercial conditions with suppliers).

\section{Literature Review}

\section{Data and results}

In our research, we have used the financial data from the companies being analyzed for 2008 and 2013 (see Table 1) and investor presentation materials from the investor relations websites of the companies.

Our analysis shows (Picture 2) that the ROE of the companies explains the difference and positive relationship of the $\mathrm{P} / \mathrm{B}$ ratio. A higher $\mathrm{ROE}$ explains a higher $\mathrm{P} / \mathrm{B}$ ratio of the retail companies. 


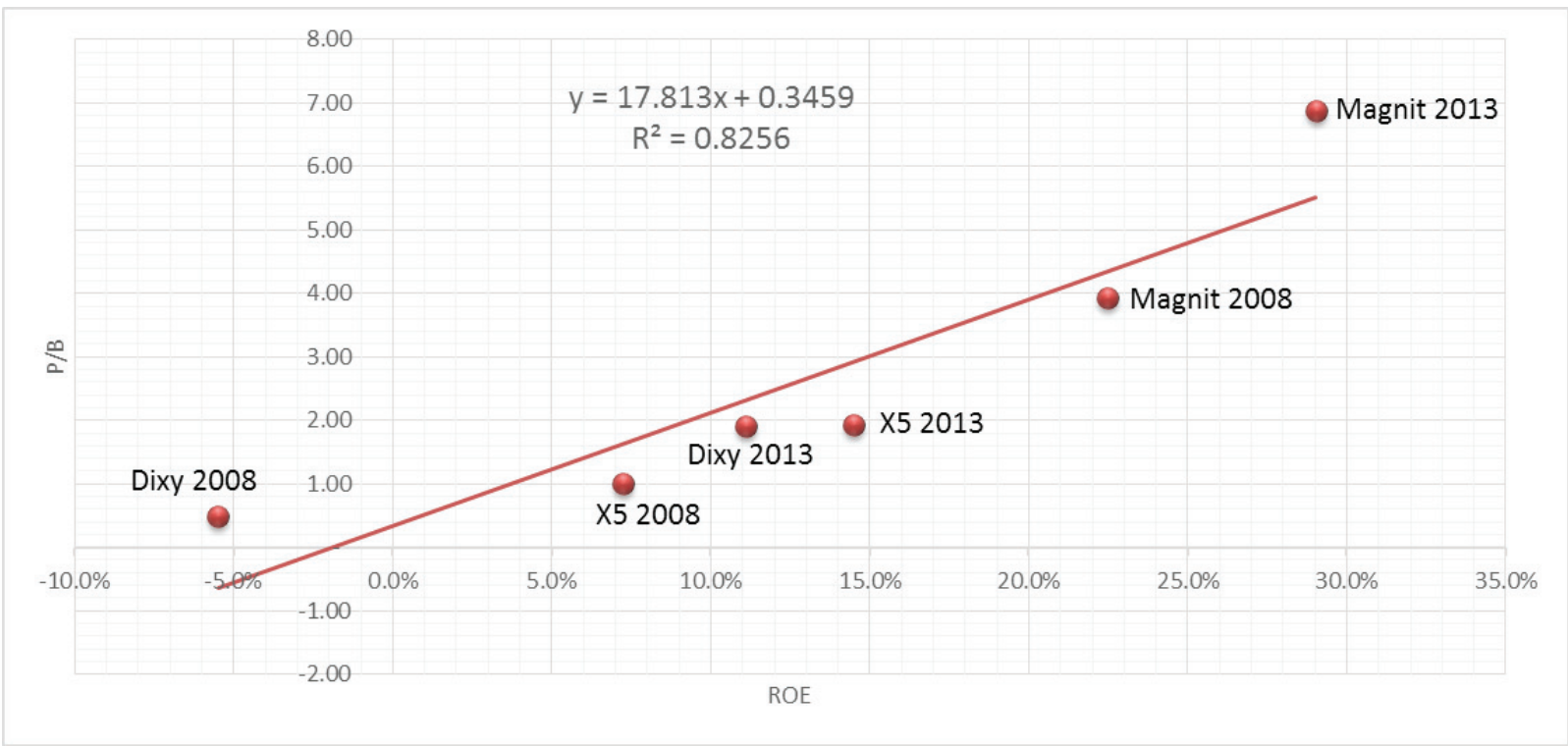

Picture 2. Relationship of $P / B$ ratio by $R O E$

As can be seen from Table 3, the companies showed improvements in ROE mainly through the net profit margin improvement. The asset turnover ratio only showed a positive trend for X5 Retail Group. As for financial leverage, we can see that Magnit and Dixy reduced it. while only X5 Retail Group increased it slightly.

Table 3

ROE decomposition analysis by companies for 2008 and 2013

\begin{tabular}{|c|c|c|c|}
\hline & 2008 & 2013 & $\%$ \\
\hline ROE (Magnit) & $22,5 \%$ & $27,0 \%$ & $+20,2 \%$ \\
\hline Net margin (Magnit) & $3,5 \%$ & $5,7 \%$ & $+62,6 \%$ \\
\hline Asset turnover (Magnit) & 2,9 & 2,2 & $-23,4 \%$ \\
\hline Financial leverage (Magnit) & 2,2 & 2,1 & $-3,5 \%$ \\
\hline ROE (X5) & $7,2 \%$ & $14,5 \%$ & $+100,2 \%$ \\
\hline Net margin (X5) & $1,4 \%$ & $2,1 \%$ & $+44,6 \%$ \\
\hline Asset turnover (X5) & 1,5 & 1,8 & $+23,3 \%$ \\
\hline Financial leverage (X5) & 3,5 & 3,8 & $+12,3 \%$ \\
\hline ROE (Magnit) & $-5,5 \%$ & $11,1 \%$ & $+101,9 \%$ \\
\hline Net margin (Dixy) & $-0,7 \%$ & $1,7 \%$ & $+152,5 \%$ \\
\hline Asset turnover (Dixy) & 2,2 & 2,2 & $+0,7 \%$ \\
\hline Financial leverage (Dixy) & 3,7 & 2,9 & $-20,6 \%$ \\
\hline
\end{tabular}

We have performed a vertical analysis of P\&L in order to understand on which level the companies concentrated on the net margin improvement. We have analyzed the gross margin and SG\&A/ Sales. As it can be seen, Magnit and Dixy improved the EBIT margin and hence net margin by improvement in gross margin, but the SG\&A/Sales ratio increased. By contrast, X5 Retail Group improved the EBIT margin by reducing SG\&A/Sales ratio.

Table 4

\begin{tabular}{|c|c|c|}
\multicolumn{1}{|c}{ EBIT } & margin & dri \\
\hline & 2008 & 2013 \\
\hline Gross margin (Magnit) & $22 \%$ & $29 \%$ \\
\hline SG\&A/Sales (Magnit) & $16 \%$ & $20 \%$ \\
\hline EBIT margin (Magnit) & $5,9 \%$ & $8,7 \%$ \\
\hline Gross margin (X5) & $26 \%$ & $24 \%$ \\
\hline SG\&A/Sales (X5) & $22 \%$ & $20 \%$ \\
\hline EBIT margin (X5) & $3,3 \%$ & $4,7 \%$ \\
\hline Gross margin (Dixy) & $26 \%$ & $31 \%$ \\
\hline
\end{tabular}

analysis 


\begin{tabular}{|l|l|l|}
\hline SG\&A/Sales (Dixy) & $25 \%$ & $27 \%$ \\
\hline EBIT margin (Dixy) & $0,9 \%$ & $4,1 \%$ \\
\hline
\end{tabular}

The classic ROE decomposition model (in the form of the DuPont model) does not help when examining detailed performance drivers. Each company is unique and it is necessary, for example, to look at gross margins, because this is a key to identify if something is wrong with the profit model of the company or the inventory turnover in order to understand how efficiently the company is using the inventory. To see what factors each company needs to focus on we will use the Ertsgamma model (Vashakmadze, 2013). This model is a visual comparison of the 12 factors that affect ROE (Equation 3).

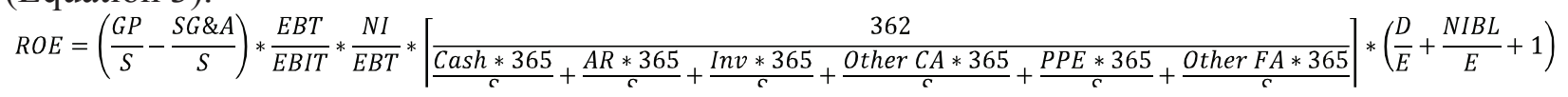

where

\begin{tabular}{|c|c|}
\hline S - sales; & Inv - inventory; \\
\hline GP - gross profit; & Other CA - other current assets; \\
\hline SG\&A - selling general and administrative expenses; & NIBL - non-interest bearing liabilities; \\
\hline EBIT - earnings before interest and expense; & PPE - property, plant and equipment; \\
\hline EBT - earnings before tax; & Other FA - other fixed assets; \\
\hline NI - net income; & D - book value of debt; \\
\hline Cash - cash and cash equivalents; & E - book value of equity; \\
\hline AR - accounts receivable; & \\
\hline
\end{tabular}

The Ertsgamma model immediately helps to identify in which areas one company has a better ratio compared to another company and helps to formulate the hypothesis for further analysis. As can be seen from Pictures 3 and 4, Magnit is keeping leadership in the financial cost ratio, involving cash management, receivables management, turnover of other current assets, turnover of other fixed assets, D/E (gearing) and non-interest bearing liabilities.

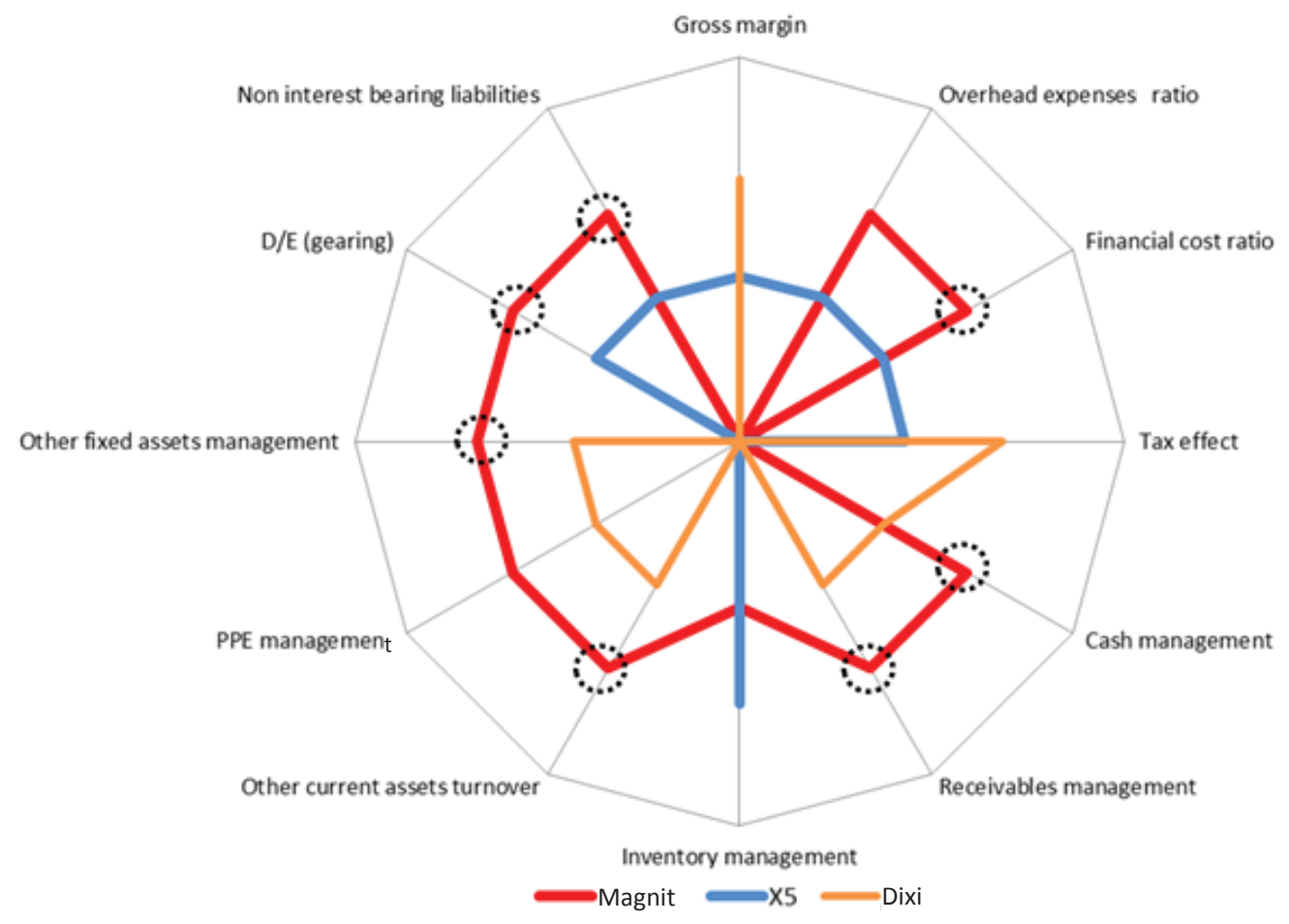

Picture 3. Comparative analysis of Magnit (the red line), X5 Retail Group (the blue line) and Dixy (the orange line) using the Ertsgamma model, 2008. 


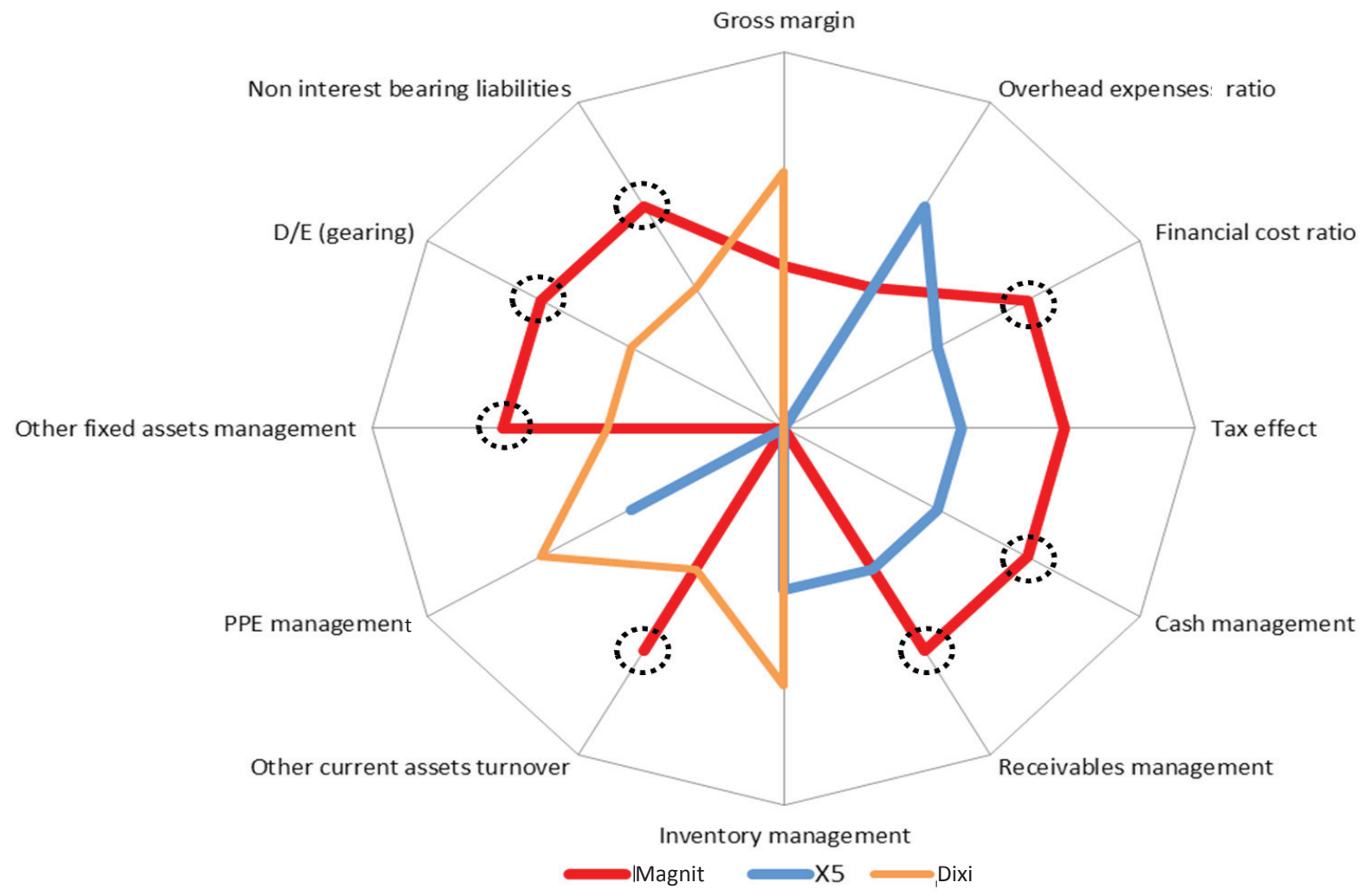

Picture 4. Comparative analysis of Magnit (the red line), X5 Retail Group (the blue line) and Dixy (the orange line) using the ertsgamma model, 2013.

In our brief literature review, we have mentioned that effective supply chains are becoming increasingly importantnfor the financial performance of retailers (Ganesan et al., 2009). Since Russia is a very large country, we think that logistics and effective supply chain management using distribution centers can be critical for the profit margins of Russian retailers. In order to test this, we have calculated a Store/DC (distribution center) ratio for each retailer. We have found out that a higher Store/DC ratis strongly correlates with the ROE of the company (Picture 5).

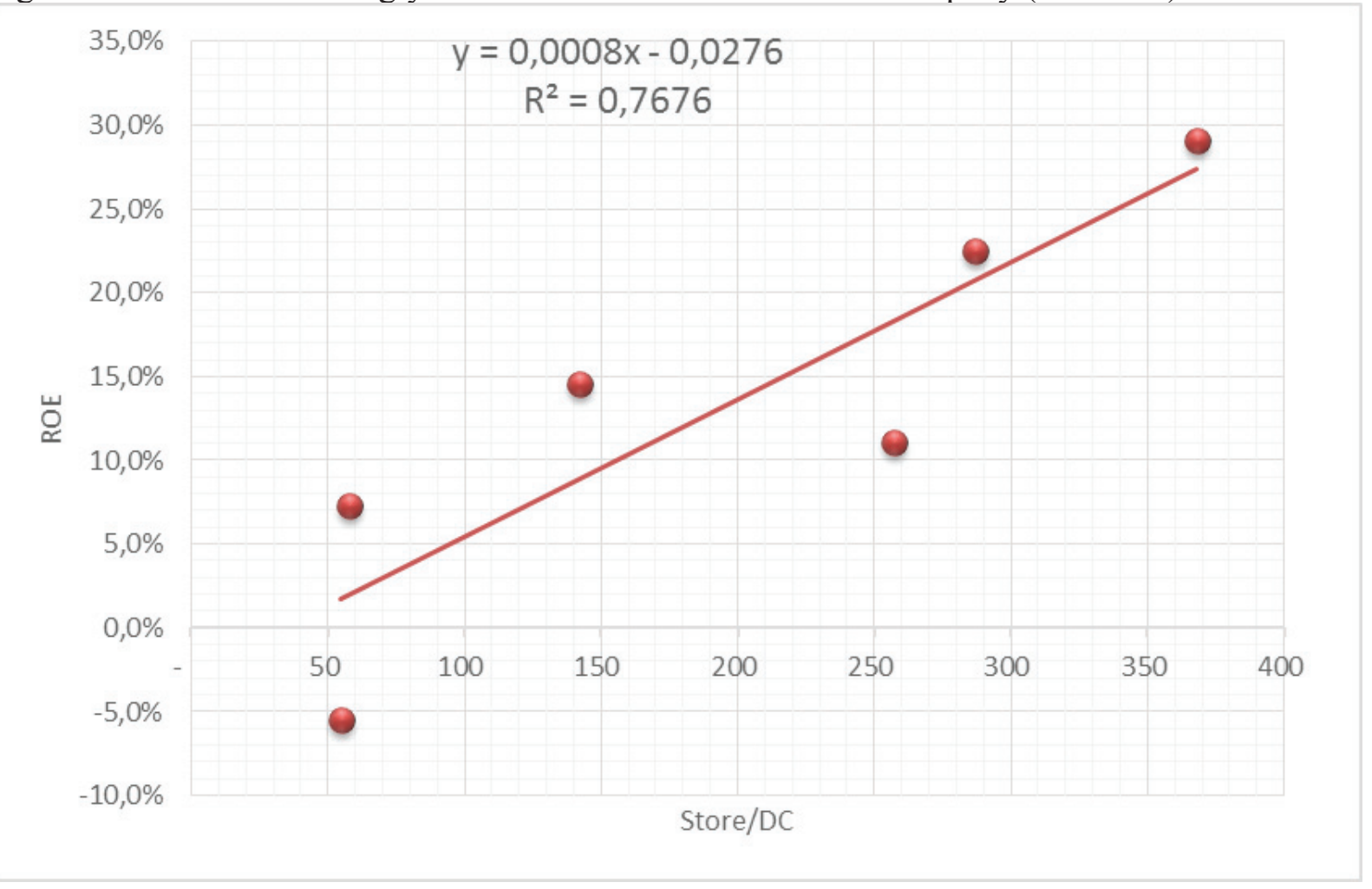

Picture 5. Relationship of ROE and Store/DC ratio 


\section{Interpretation of results}

As can be seen from table 5, each retail company has a unique approach to the management of industry relevant factors (cross-docking, franchising, regionalization of the product matrix, decentralization, focus on core activity and commercial conditions with suppliers) that affect performance and, hence, value creation.

Table 5

Vertical analysis of P\&L of the companies for 2008 and 2013

\begin{tabular}{|c|c|c|c|}
\hline & Magnit & X5 Retail Group & Dixy \\
\hline $\begin{array}{c}\text { Focused \& direct investments to cross-docking centers } \\
\text { together with expanding retail outlet development }\end{array}$ & High & Medium & Medium \\
\hline $\begin{array}{c}\text { Franchising vs. own development approaches in chain } \\
\text { extension }\end{array}$ & Low & High & Medium \\
\hline Product matrix together with suppliers regionalization & High & Low & Medium \\
\hline Management decision decentralization & High & Low & Low \\
\hline Focus on core activity & High & Low & Medium \\
\hline Specifics in commercial conditions with the suppliers & See Table 6 & & \\
\hline
\end{tabular}

\section{What are the core common drivers that led the above-described retail chains? \\ Focused and direct investments to cross-docking centers together with expanding retail outlet development}

After 2008, Lev Khasis (CEO, X5 Retail Group) declared that X5 is not a retail chain but a logistics chain provider, which shocked the whole retail market. He also added that it is not possible to become the market leader without caring about the supply chain that services and adjusts the growing retail business in terms of the number of outlets. Cross- docking was the solution in such a large country as Russia. For all Russian retailers, the only rule for the suppliers was "direct delivery", which is out of cost efficiency if the retail chain is growing regionally and federally. For example, the direct delivery of 10 pallets directly to 10 retail outlets in the Moscow region can cost 1000-1200 USD to the supplier, as the direct delivery to the central HUB (cross-dock) may cost 200-300 USD for 1 truck with 10 pallets. After suppliers bring the common truck to the cross-dock, the retail chain logistics starts shuttling the exact orders directly to retail outlets. These competences in the supply chain management (SCM) are shifted directly from suppliers and retailers to 3-4PL supply chain outsource providers. Magnit started investing into the cross-docking system from the beginning, X5 - after the M\&A deal Perekrestok-Pyaterochka and Dixi - actively from 2009-2010. The suppliers' reaction is pragmatically transparent - choosing between the chains with cross-docking they will prefer operating with the first ones - which is proved financially as the cost per every logistics operation. Many Russian retailers such as The 7th Continent and Magnolia operate without crossdockings and face such problems as expanding the chain in new stores, in new square meters, in new shelves. The suppliers could not support this growth by means of the growing logistics service level support, which led these chains to empty shelves and created a lack of motivation from the suppliers' point of view.

\section{Franchising vs own development approaches in chain extension}

Another core factor for the successful retail chain development in Russia is the right proportion of own store owning in relation to franchising developments. Magnits' successful development might be explained as the non-franchise base development by focusing on opening their own retail outlets. Magnit's high gross margin rate can be explained by the fact that Magnit is adjusting the product matrix to the specific region of presence, which means that local suppliers' domination over the federal ones is 70/30. An absolutely different development strategy has been chosen by X5 Retail Group management by giving preference to franchising. The model works using the following principle: X5 is signing a franchising contract with a franchisee for 5-7 years with the obligation 
for the latter to launch 20-30 stores inside the considered region. After the end of the franchising contract the franchisee has the option to sell out the cultivated chain back to X5 with the set (8-10) multiple to EBITDA if the margin is in the range of $10-15 \%$ (the personal interview with Valery Tarakanov, General Director at X5 Retail Group Franchising Department, March 2010). If the deal is done, the franchisee is investing cash in X5 to open 40-50 stores. The end of one story occurred when X5 proposed a joint venture to the franchisee in the region of presence when the market share exceeded 20-25\% (Bashkortostan, Pyaterochka case). This strategy means that, at the end of the day, X5 is operating in around $65-70 \%$ of stores in the franchising format with a low rate of the product matrix regionalization and adjustment, which leads to a high level of attacks on the gross margins and a lack of resources required for opening their own stores. That is why X5 Retail Group is leveraging credit resources for business extension in terms of store opening and development. After analyzing two different models of business growth, Dixy has chosen the way of Magnit with a low rate of franchise based development.

\section{Product matrix together with suppliers' regionalization}

Those who propagate current marketing trends claim that the more one is adjusted to local consumer markets, the more business benefits can be gained. Russia is a large country with 85 regions where people demonstrate a number of different forms of consumer behavior. From the beginning the strategy of Magnit was just product matrix regionalization and adjustment to each local area of presence, as it is not possible to compare people's attitudes to consumption in the eastern part of Russia with those in the west. Besides, by making your matrix regional you create a regional pull of suppliers that are more dependent on the retailer than the big federal ones. By using this strategy Magnit had a better performance in gross margin generation. X5 Retail Group used the opposite strategy. Around $70 \%$ of their product matrix is created by multinational and Russian federal suppliers that are unifying the product matrix. This strategy brings X5 more dependency on big suppliers and less gross margin control. In this case it takes more time for supplier replacement to occur. Dixy follows a more moderate strategy where $50 \%$ of the matrix is created regionally and $50 \%$ is created globally on the federal level.

\section{Management decision decentralization}

In this subject there are two approaches to the retail industry. The first one supports the idea where the central office controls all contracts, all cash flow and passes all decisions about investments in the chain expansion and development. In this case, the role of the center is dominant in management. The second approach involves giving more freedom in decision making to regional subsidiaries responsible for the regional development. Here the role of the central office is in coordinating, in being supportive and in creating the conditions for subsidiaries to be engaged in the successful business development. One of the key factors that brought Magnit to being the absolute retail leader in Russia was the fact that all decision making regarding the product matrix, number, format and store sizes, commercial conditions with suppliers were provided to regional subsidiaries that could envisage better local positions and needs. X5 Retail Group has been afraid of losing the regional control, which has kept the decision making in Moscow, and from time to time the time, speed and quality in decision making regarding the regional development creates inertia in a company with regard to taking decisions over the regional capex and opex. Following Magnit, Dixy creates more benefits in the regional development, the only limitations being the working capital that does not allow them to expand to the scale of Magnit.

$$
\text { Focusing on the core activity in the retail and cross-docking development }
$$

vs investing in non-related alternative assets.

X5 Retail Group, as a member of the Alpha Group (a multi-business holding), is widely involved in diversification as part of corporate strategy. Together with retail M\&As, X5 invests in nonrelevant and non-related businesses in the pharmaceutical industry, fashion and entertainment. X5 owners, as owners of the TNK oil company, the Alpha Bank financial institution, the Vimpelcom telecommunication company (via Altimo), placed X5 in the fourth priority place for the development in order to bring the chain to less core shareholder development focus. Dixy is a diversification for the 
Merkuriy group, the leading tobacco distributor in Russia. The prioritization of Dixy's development is coming more important as the tobacco industry is declining after tough state restrictions and regulations. In this case, the business focus for Dixy's development in various major aspects depends on the situation in the RF tobacco market which is not proper for building up a leading retail chain. Magnit retains a 20 year focus on retail development by not investing in non-relevant and nonrelated core business projects. Magnit cosmetics is a new project for Magnit, with developing the grocery format and adding value to Magnit food chain, however, without taking focus out from the core business development.

Specifics in commercial conditions with suppliers - comparative analysis:

Table 6

Comparative analysis of commercial conditions with suppliers

\begin{tabular}{|c|c|c|c|}
\hline Parameter & Magnit & X5 RG & Dixi \\
\hline $\begin{array}{l}\text { Purchasing price for the product } \\
\text { (suppliers' prices for the chain) }\end{array}$ & Regular & Regular - & Regular + \\
\hline $\begin{array}{l}\text { On-invoice discount (the discount } \\
\text { that the supplier is giving before the } \\
\text { delivery and fixes in the invoice) }\end{array}$ & Non-implemented & Implemented & Implemented \\
\hline $\begin{array}{l}\text { Off-Invoice discounts (the discounts } \\
\text { that the supplier gives after the } \\
\text { delivery by decreasing the buyer's } \\
\text { accounts receivable) }\end{array}$ & Implemented & Non-implemented & Non - implemented \\
\hline $\begin{array}{l}\text { Average retro bonus size (bonus paid } \\
\text { by the supplier to the chain for the } \\
\text { commercial plan fulfillment) }\end{array}$ & $25-30 \%$ & $20-25 \%$ & $15-20 \%$ \\
\hline $\begin{array}{l}\text { Average post payment conditions in } \\
\text { days }\end{array}$ & 45 , no credit limits & 90 , no credit limits & $45-60$, no credit limits \\
\hline $\begin{array}{l}\text { Average logistics service level to be } \\
\text { demonstrated by the supplier }\end{array}$ & & $\begin{array}{l}97 \% \\
93 \% \\
90 \%\end{array}$ & \\
\hline $\begin{array}{l}\text { New stores launch programs with } \\
90 \% \text { discount for } 3 \text { months }\end{array}$ & Yes & No & No \\
\hline Return of non sold products & No & Yes & Yes \\
\hline
\end{tabular}

\section{Conclusion}

In this article we have explained the business factors that mostly influenced the corporate ROE and the price-per-book value of the company of the Russian food retail industry. After the analysis of three Russian retail chains we have come to the conclusion that the retail business development in Russia (apart from the consumer market factors) mostly depends on efficient management in operations and on having good commercial conditions with suppliers. At the same time there is a direct impact on the retailers' gross margins from the specific operational solutions like crossdocking implementations.

\section{The final conclusions of this article are as follows:}

1. Operational excellence brings more gross marginality and the ability for the retail chains to grow organically by investing in self-growth from their own working capital. The key focus for the retailers, along with trade space expansion, should be investments in the logistics infrastructure.

2. As the chains spread on a countrywide level, the commercial and development policy needs to be decentralized by giving more decision making powers to regional subsidiaries.

3. Retail focus and concentration should mostly be dedicated to the core business at the growth stage with minimum attention being given to diversification in non-related businesses.

4. Commercial conditions for the suppliers are the basis for retail margin generation and these should be regularly reconsidered to find the mutual balance (win-win) with the partner, which will allow the supplier to operate at a profit. 


\section{Referenses}

1. Billige, M. (2013). Customer demands for promotions and price aggressive competitors cost Consumer Packaged Goods firms dearly. Unpublished manuscript, Simon-Kucher Partners. Available from http://www.simon-kucher.com/en-gb/news/customer-demands-promotionsand-price-aggressive-competitors-cost-consumer-packaged-goods-firms.

2. Chen, Peter F., and Guochang Zhang. Profitability, earnings and book value in equity valuation: A geometric view and empirical evidence. Hong Kong University of Science and Technology Working Paper (2003).

3. Fama, Eugene F., French, Kenneth R., Profitability, investment and average returns, Journal of Financial Economics 82 (2006) 491-518.

4. Ganesan, Shankar, George, Morris, Jap, Sandy, Palmatier, Robert W., Weitz, Barton (2009), Supply chain management and retailer performance: Emerging trends, issues, and implications for research and practice, Journal of Retailing, 85 (1, 2009) 84-94.

5. Halsey, Robert F. Using the residual-income stock price valuation model to teach and learn ratio analysis. Issues in Accounting Education 16.2 (2001): 257-272.

6. Halsey, R. F., and V. E. Soybel. 2001. Mean reversion of ROE components. Working paper, Babson College.

7. Sorescu, Alina, Frambach Ruud, T., Singh Jagdip, Rangaswamy, Arvind, Bridges, Cheryl (2011), Innovations in Retail Business Models, Journal of Retailing, 87S (1, 2011) S3-S16.

8. Van Zelst S. et al. Logistics drivers for shelf stacking in grocery retail stores: Potential for efficiency improvement, International Journal of Production Economics. - 2009. - T. 121. - №. 2. - C. 620-632.

9. Wilcox, Jarrod W. The P/B-roe valuation model. Financial Analysts Journal (1984): 58-66.

10. Vashakmadze T. 2013. Introducing the Ertsgamma model for performance and M\&A analysis. Economics and Entrepreneurship, vol. 7, no. 6, 
Financial data of Magnit, X5 Retail Group and Dixy for 2008 and 2013.

\begin{tabular}{|c|c|c|c|c|c|c|}
\hline MLN. RUB & & 2008 & & & 2013 & \\
\hline Balance sheet & Magnit & $\begin{array}{l}\text { X5 Retail } \\
\text { Group }\end{array}$ & Dixy & Magnit & X5 Retail Group & Dixy \\
\hline Cash and cash equivalents & 115055 & 276837 & 1289799 & 181218 & 232557 & 4397044 \\
\hline Receivables & 907 & 188986 & 944942 & 19296 & 420565 & 6039855 \\
\hline Inventory & 323336 & 482158 & 3272828 & 1713925 & 1144648 & 10102566 \\
\hline Other current assets & 53880 & 325408 & 1271583 & 140603 & 539225 & 2297460 \\
\hline PPE & 1331064 & 3097540 & 12067845 & 5962817 & 4124704 & 34061088 \\
\hline Othe fixed assets & 19813 & 1289890 & 2737973 & 176063 & 2762568 & 23148738 \\
\hline Total assets & 1844055 & 5660819 & 21584970 & 8193922 & 9224267 & 80046751 \\
\hline Payables & 484857 & 1174144 & 5719936 & 1471796 & 2476380 & 21468165 \\
\hline Short term debt & 221380 & 578433 & 1236026 & 1109705 & 937381 & 327808 \\
\hline Other current liabilities & 119938 & 520627 & 1032291 & 355161 & 829978 & 1231718 \\
\hline Long term debt & 123040 & 1480968 & 7098224 & 1143981 & 2439499 & 28560115 \\
\hline Other long term liabilities & 58052 & 268214 & 604015 & 258553 & 163778 & 930677 \\
\hline Total equity & 836788 & 1638433 & 5894478 & 3852726 & 2377251 & 27528268 \\
\hline Total liabilities and equity & 1844055 & 5660819 & 21584970 & 8191922 & 9224267 & 80046751 \\
\hline \multicolumn{7}{|l|}{ Income statement } \\
\hline Sales & 5347806 & 8353250 & 48325088 & 18201924 & 16784728 & 180504463 \\
\hline Cost of sales & 4188271 & 6206324 & 35783573 & 13012807 & 12691916 & 125134620 \\
\hline Gross profit & 1159535 & 2146926 & 12541515 & 5189117 & 4092812 & 55369843 \\
\hline $\begin{array}{l}\text { Selling, general and } \\
\text { administrative expenses }\end{array}$ & 850288 & 1698524 & 11026117 & 3639314 & 3477680 & 47811799 \\
\hline Other* & -3622 & 173058 & 1067483 & -37011 & -181084 & 70242 \\
\hline EBIT & 312869 & 275344 & 447915 & 1586814 & 796216 & 7487802 \\
\hline Interest & 53280 & 148505 & 552751 & 150177 & 343344 & 3397397 \\
\hline EBT & 259589 & 126839 & -104836 & 1436637 & 452872 & 4090405 \\
\hline Tax & 71674 & 8106 & 219171 & 318189 & 107989 & 1034734 \\
\hline Net income & 187915 & 118733 & -324007 & 1118448 & 344883 & 3055671 \\
\hline
\end{tabular}

* From X5 Retail Group we have excluded impairement of goodwill in the amount of 2257020 